\title{
Política fiscal anticíclica, crise financeira internacional e crescimento econômico no Brasil
}

\author{
SÉRGIO RICARDO DE BRITO GADELHA*
}

Countercyclical fiscal policy, international financial crisis and economic growth in Brazil. This study analyzes the long run equilibrium relationship and causality between economic growth and public expenditure in Brazil covering the period 1980-2008. The empirical results of the Granger causality test in a multivariate framework have shown up the importance of public investments not only to face the adverse effects of the international financial crisis, but also in stimulating the economic growth. Also, the results indicate the need of controlling the growing path of other current expenditure, social security and public debt.

Keywords: countercyclical fiscal policy; government expenditures; economic growth; Granger causality.

JEL Classification: C32; E62; F43; H11; H50.

\section{INTRODUÇÃO}

A relação entre crescimento econômico e política fiscal tem sido investigada na literatura por meio de duas variáveis, gastos públicos e renda nacional, e os resultados empíricos obtidos possuem importante relevância teórica e política. Sob o aspecto teórico, os primeiros estudos dessa frente de pesquisa testaram duas hipóteses tradicionais sobre gastos públicos: a hipótese wagneriana e a hipótese keynesiana. A Lei de Wagner considera os gastos públicos como uma variável comportamental, ou seja, endógenos, postulando que o crescimento na atividade

\footnotetext{
* Analista da Secretaria do Tesouro Nacional. Mestre e doutorando em Economia pela Universidade Católica de Brasília. E-mail: sergio.gadelha@fazenda.gov.br. O autor agradece aos editores e aos pareceristas anônimos por comentários e sugestões. As opiniões expressas neste trabalho são de exclusiva responsabilidade do autor, não expressando necessariamente a opinião da Secretaria do Tesouro Nacional. Submetido 7/jul./2009; Aprovado 18/jun./2010.
} 
econômica causa um aumento nas atividades governamentais. A teoria keynesiana tradicional afirma que, no curto prazo, a política fiscal tem um efeito positivo sobre o nível de atividade econômica, através do multiplicador dos gastos. Logo, os gastos públicos são considerados um instrumento exógeno de política econômica, causando mudanças no nível agregado do PIB real no curto prazo e sendo usados para corrigir as flutuações cíclicas da economia.

Entretanto, a partir da contribuição de Giavazzi e Pagano (1990), iniciou-se um novo debate sobre os efeitos da política fiscal na atividade econômica. Especialmente, existe um grande número de estudos empíricos postulando que, sob determinadas circunstâncias, uma política fiscal contracionista pode ter efeitos expansionistas sobre o consumo, o investimento e o produto da economia. Trata-se da análise dos chamados efeitos não keynesianos da política fiscal, baseados nas evidências de contrações fiscais expansionistas e expansões fiscais contracionistas, que resultam do impacto da política fiscal corrente levando em conta a expectativa e a confiança dos agentes privados nas mudanças de políticas econômicas futuras, em particular, na resposta do consumo privado a maiores mudanças fiscais. Assim, ajustes fiscais baseados em corte de gastos podem gerar crescimento econômico, ao invés de recessão, através do aumento do investimento privado e maior confiança dos agentes econômicos.

No Brasil, a relação de causalidade entre gastos públicos e crescimento econômico é tema não consensual no atual debate acadêmico, com importantes implicações de política econômica. Além disso, no momento atual, o esforço fiscal anticíclico do governo ante a crise de liquidez internacional que se alastrou pelo mundo a partir de meados de setembro de 2008 tem-se baseado em um conjunto de medidas voltadas a estimular o crédito, por exemplo, as desonerações tributárias, o pacote habitacional, redução da meta de superávit primário e a liberação de várias linhas de crédito por parte dos bancos oficiais.

Apesar do maior esforço fiscal do governo federal na geração de superávit primário a partir de 1999, um número de autores (Ramos, 2001; Rocha e Picchetti, 2003; Giambiagi, 2008) atribui o baixo crescimento brasileiro a uma política fiscal caracterizada por baixos investimentos públicos, elevados gastos previdenciários, elevada dívida pública, ineficiência na política de pessoal, elevada despesa corrente, entre outros, sendo esses fatores apontados como a origem da vulnerabilidade para o crescimento econômico de longo prazo e que inviabilizam o ajuste fiscal.

Além disso, há um consenso de que a adoção de uma política fiscal anticíclica via expansão dos gastos como reação à atual crise financeira internacional tem o seu limite imposto pelo seu impacto sobre o crescimento de longo prazo, assim como o risco de renascerem dúvidas quanto à sustentabilidade fiscal de países com dívida e déficit públicos elevados. É relevante questionar em que condições os benefícios de curto prazo de uma política fiscal expansionista no combate à desaceleração econômica contribuirá para o crescimento de longo prazo da economia brasileira.

Por essa razão, o objetivo deste artigo é investigar se no Brasil a política fiscal possui efeitos keynesianos, não keynesianos ou wagnerianos em relação ao produto da economia. Este estudo deve representar uma contribuição para o debate 
acadêmico e na formulação de políticas, porque se analisa a reação da política fiscal aos efeitos da atual crise econômica e os impactos sobre o crescimento econômico no longo prazo.

Sob o aspecto de formulação de política fiscal anticíclica, a investigação é essencial por cinco razões. Primeiro, a existência de causalidade de Granger positiva do produto para os gastos públicos $(y \rightarrow g)$ é consistente com a Lei de Wagner, significando que o crescimento econômico estimula o aumento dos gastos. Segundo, a existência de causalidade de Granger positiva dos gastos públicos para o produto $(g \rightarrow+y)$ apoia a hipótese keynesiana, sendo um indicativo de que os gastos públicos podem ser usados para corrigir flutuações cíclicas da economia e, dessa forma, estimular o crescimento econômico. Terceiro, a existência da relação de causalidade de Granger negativa dos gastos públicos para o produto $(g \rightarrow-y)$ apóia a hipótese dos efeitos não keynesianos da política fiscal, de modo que a adoção de uma política fiscal contracionista poderá resultar em efeitos expansionistas sobre o produto. A existência de relação de bicausalidade de Granger corrobora a prevalência da hipótese wagneriana em conjunto com as hipóteses keynesiana ou não keynesiana da política fiscal em relação ao produto $(g \leftrightarrow y)$. Finalmente, a ausência de causalidade postula inexistência de relação entre as variáveis analisadas $(g \leftrightarrow y)$.

Os resultados empíricos obtidos evidenciaram a prevalência da hipótese keynesiana nos investimentos públicos, destacando-se assim sua importância em estimular o crescimento econômico de longo prazo. No curto prazo, os resultados indicam a necessidade de se controlar a trajetória crescente das demais despesas correntes, benefícios previdenciários e dívida pública, bem como elevar os gastos com investimentos públicos e transferências governamentais para enfrentar os efeitos adversos da atual crise financeira internacional.

O estudo está organizado da seguinte forma. A segunda seção apresenta a revisão da literatura empírica. A terceira seção apresenta as variáveis envolvidas na análise. A quarta seção descreve o tratamento econométrico, onde são apresentados os testes de raízes unitárias e de causalidade de Granger. A quinta seção reporta e analisa os resultados. Finalmente, a sexta seção conclui o estudo.

\section{REVISÃO DE LITERATURA}

A revisão de literatura está dividida em duas subseções: “Artigos que não usam causalidade", baseada em estudos sobre não linearidades da política fiscal; e "Artigos que usam causalidade”, fundamentada em análise de regressões lineares.

\section{Artigos que não usam causalidade}

Giavazzi e Pagano (1990) identificaram casos de políticas fiscais contracionistas com efeitos expansionistas durante os planos de estabilização na Dinamarca (1983-1986) e na Irlanda (1987-1989). O aumento do valor de mercado do estoque 
de riqueza causado pela queda dos juros e as expectativas a respeito do futuro (forward looking) desempenharam um papel importante na dinâmica de crescimento por causa do efeito da credibilidade da política fiscal no consumo privado.

De acordo com Bertola e Drazen (1993), os efeitos das expectativas podem induzir a uma relação não linear entre política fiscal e consumo privado. Se o corte do orçamento governamental sinaliza com credibilidade um corte permanente nos gastos, poderá se observar um aumento no consumo agregado.

Analisando a resposta do consumo privado à política fiscal em períodos normais e fora de períodos normais, em uma amostra de países da OCDE no período 1970-1992 Giavazzi e Pagano (1996) encontraram evidências de que a política fiscal exercia efeitos keynesianos em períodos normais, observando-se efeito crowding-in ocorrendo entre consumo privado e consumo público enquanto elevados impostos reduziam o consumo privado, mas não foram observados efeitos não keynesianos fora dos períodos normais.

Alesina e Perotti (1995 e 1997) argumentaram que um dos determinantes para a existência de não linearidade da política fiscal é a composição do ajustamento. Nesse sentido, foram identificados dois tipos de consolidação fiscal: a) Tipo 1: ajustamento que se baseia em cortes de gastos em transferências, seguridade social, salários no setor público e no emprego; b) Tipo 2: ajustamento que se baseia em aumento de impostos e cortes nos investimentos públicos, e esse tipo de ajustamento tem baixa probabilidade de sucesso. Os resultados evidenciaram que as consolidações fiscais bem-sucedidas ocorriam quando a melhora orçamentária era obtida cortando-se as despesas com os salários de funcionários públicos e benefícios previdenciários.

Sob essa perspectiva, Rocha e Picchetti (2003) analisaram os períodos de consolidação fiscal e de estímulo fiscal, bem como a composição dos ajustamentos fiscais na economia brasileira, durante o período de 1999 a 2000. Os resultados indicaram os anos 1994 e 1999 como pontos de consolidação fiscal, apesar de que a consolidação de 1994 não pode ser considerada um sucesso porque nos anos seguintes a razão dívida/PIB cresceu continuamente. Além disso, os resultados identificaram ajustamento do Tipo 2, no sentido de que foram feitos cortes no investimento público, enquanto os salários e transferências permaneceram inalterados.

Analisando regressões em painel de funções de consumo, a partir de dados fiscais de 19 países da OCDE durante o período 1965-1994, Perotti (1999) argumenta que uma dívida alta, ou que cresce rapidamente, é um dos fatores considerados para que uma consolidação fiscal tenha uma maior probabilidade de ser expansionista. Os resultados indicaram que os choques nos gastos possuíam efeitos keynesianos, com dívidas ou déficits pequenos, mas efeitos não keynesianos, com dívida ou déficits elevados.

\section{Artigos que usam causalidade}

Singh e Sahni (1984) investigaram as direções e o padrão de causalidade entre a renda nacional e os gastos públicos, agregados e por função, na Índia, entre os anos 1950 e 1981, utilizando o teste de causalidade de Granger desenvolvido em 
uma estrutura bivariada. Usando dados anuais dos gastos públicos per-capita e renda nacional per-capita, ambos em preços correntes e constantes (1970-1971), os principais resultados obtidos foram: (i) relação de bicausalidade, no sentido de Granger, entre gastos públicos e renda nacional, de modo que não se pode determinar se os gastos públicos na Índia eram wagnerianos ou keynesiano; (ii) relação de bicausalidade, no sentido de Granger, dos gastos públicos referentes às funções social e desenvolvimento, administração e defesa nacional, em relação ao crescimento da renda nacional; (iii) os serviços da dívida pública Granger-causa a renda nacional, de modo negativo.

Conte e Darrat (1988) estudaram a relação de causalidade entre o crescimento do setor público e as taxas reais de crescimento econômico em 22 países da OCDE, e encontraram os seguintes resultados: (i) a expansão do setor público Granger-causa a taxa de crescimento econômico real de modo significante, mas com efeitos negativos para dois países (Austrália e Irlanda) e com efeitos positivos para outros três países (França, Itália e Portugal); (ii) relação de bicausalidade de Granger observada para Irlanda, Itália, Portugal, Suíça e Reino Unido; e (iii) ausência de relação de causalidade entre os seguintes países: Bélgica, Canadá, Dinamarca, Grécia, Holanda, Noruega, Espanha, Estados Unidos e Alemanha Ocidental. A principal contribuição indica que o setor público não afeta o crescimento econômico da maioria dos países da OCDE.

Ghali (1997) utilizou o modelo de crescimento endógeno de Barro (1990) para investigar a relação entre gasto governamental e crescimento econômico na Arábia Saudita, no tocante às variáveis taxa de crescimento do PIB real per-capita e a relação gasto governamental/PIB. Utilizando a modelagem dos vetores autorregressivos (VAR), os resultados obtidos mostraram nenhuma evidência de que o gasto governamental possa aumentar o produto per-capita da Arábia Saudita. Por outro lado, os resultados indicaram que a taxa de crescimento do PIB real per-capita Granger-causa a relação gasto governamental/PIB, segundo a hipótese wagneriana dos gastos públicos.

Fasano e Wang (2001) investigaram as relações de curto e longo prazo entre gastos públicos e crescimento do PIB real dos países membros do Conselho de Cooperação do Golfo (Bahrein, Omã, Qatar, Emirados Árabes e Arábia Saudita), por meio da modelagem dos vetores autorregressivos com mecanismo de correção de erros (VEC). Utilizando dados do PIB a preços constantes, e das despesas de custeio e de capital, deflacionadas pelo índice de preços ao consumidor, para o período de 1980 a 1999, os resultados do teste de causalidade de Granger não indicaram evidências de que essas despesas diminuíam ou aceleravam o PIB real. Logo, os governos poderiam promover cortes de gastos públicos sem afetar, de forma negativa, o crescimento econômico.

Loizides e Vamvoukas (2005) examinaram a relação de causalidade entre o tamanho do governo e crescimento econômico do Reino Unido (1950-1995), Grécia (1948-1995) e Irlanda (1950-1995), utilizando dados anuais obtidos no Fundo Monetário Nacional e na Comissão Europeia para as seguintes variáveis: (i) relação gastos públicos/PIB, como medida do tamanho do governo; (ii) gasto público real, 
representando os gastos governamentais em bens e serviços (excluindo o pagamento de transferências), ou seja, a formação bruta de capital fixo governamental; (iii) taxa de desemprego e, (iv) índice de preços. Os resultados do teste de causalidade de Granger indicaram que: (a) o tamanho do governo Granger-causa o crescimento econômico em todos os países no curto prazo, mas no longo prazo observa-se essa relação de causalidade apenas para a Irlanda e o Reino Unido; (b) o crescimento econômico Granger-causa o tamanho do governo na Grécia e, quando se inclui a taxa de inflação, essa relação de causalidade é observada também para o Reino Unido.

Huang (2006) testou empiricamente a Lei de Wagner para a China e Taiwan no período 1979-2002 utilizando o teste de causalidade de Granger. Usando dados de PIB e gasto governamental, em termos reais, assim como de população, obtidos no International Financial Statistics do Fundo Monetário Internacional, os resultados obtidos mostraram a inexistência de relação de longo prazo entre tamanho do governo e crescimento econômico e não se confirmou a hipótese da Lei de Wagner.

\section{DADOS USADOS NO ESTUDO}

Os dados anuais de séries históricas das variáveis em análise são apresentados em termos reais, deflacionados pelo Índice Geral de Preços — Disponibilidade Interna (IGP-DI) no período de 1980 a 2008 . Como as variáveis estão em logaritmos naturais, os coeficientes estimados podem ser interpretados como as elasticidades de longo prazo do produto em relação a cada componente de gastos. Em termos agregados, a variável envolvida na análise é o PIB real $\left(p i b_{t}\right)$, cuja série histórica abrangendo o período de 1980 a 2007 foi obtida no sítio eletrônico do Instituto de Pesquisa Econômica Aplicada (IPEA) ${ }^{1}$. Para o ano de 2008 utilizou-se as informações de PIB real fornecida pelo Banco Central do Brasil.

No nível desagregado, as despesas federais são decompostos por categorias econômicas (correntes e de capital), em termos de despesas liquidadas, e as séries foram obtidas no sítio eletrônico da Secretaria do Tesouro Nacional (STN) ${ }^{2}$. De acordo com a Portaria Interministerial ${ }^{\circ} 163$, de 4/5/2001, as despesas correntes são representadas pelos seguintes grupos de natureza de despesa: (i) Pessoal e Encargos Sociais $\left(\right.$ pes $\left._{t}\right)$; (ii) Juros e Encargos da Dívida $\left(\right.$ juros $\left._{t}\right)$; (iii) Transferências a Estados, DF e Municípios $\left(\right.$ trans $\left._{t}\right)$; (iv) Benefícios Previdenciários $\left(\text { prev }_{t}\right)^{3}$; e (v)

\footnotetext{
${ }^{1}$ Disponível em: <http://www.ipeadata.gov.br>.

${ }^{2}$ Os dados desagregados por categorias econômicas e por grupos de natureza de despesa (GND) estão disponíveis em: <www.tesouro.fazenda.gov.br>, cuja Fonte é o Sistema de Administração Financeira do Governo Federal (SIAFI).

${ }^{3}$ A partir dos dados constantes no Balanço Geral da União (BGU) para os anos 1990-1992, a modalidade de despesa Benefícios Previdenciários fazia parte do grupo de despesas Pessoal e Encargos Sociais, e não de Outras Despesas Correntes, como ocorreu nos anos anteriores (1989 e antes) e nos posteriores (1993 e depois). Em consequência, para o período em foco, os valores da modalidade Benefícios Previdenciários devem ser subtraídos do grupo Pessoal e Encargos Sociais. Fonte: CCONT/STN.
} 
Demais Despesas Correntes $\left(c o r r_{t}\right)$. As despesas de capital, por sua vez, são constituídas dos seguintes grupos de natureza de despesa: (vi) Investimentos (inv $\left.t_{t}\right)$ ( vii) Inversões Financeiras $\left(i f_{t}\right)$; e (viii) Amortização da Dívida $\left(\text { div }_{t}\right)^{4}$.

Este estudo apresenta algumas limitações. Primeiro, a justificativa de se trabalhar com dados anuais reside no fato de não existirem dados mensais ou trimestrais das variáveis de despesas disponíveis para consulta pública entre os anos 1980 e início dos anos 1990, de modo que a amostra em análise se baseia apenas em 29 observações anuais. Segundo, a inclusão de variáveis dummies na modelagem de quebras estruturais pode diminuir os graus de liberdade. Terceiro, é provável que, em uma amostra pequena e com variáveis correlacionadas, os sinais das elasticidades a serem estimadas sejam opostos aos esperados.

A Tabela 1 apresenta as informações referentes aos gastos públicos federais por categoria econômica e em proporção do PIB, em termos reais. Os pesos de cada componente de despesa ao longo do tempo podem ser interpretados como medida de qualidade fiscal.

Por exemplo, os gastos com juros e encargos da dívida, adicionados aos dispêndios com a amortização da dívida, destacam-se como um dos maiores gastos do orçamento federal. Enquanto, em 1980, a soma desses gastos representava $0,56 \%$ do PIB real, durante os anos 1900 e 2000 apresentaram percentuais bastante elevados e, em 2008, atingiram 16,25\% do PIB real. Por um lado, o crescimento das despesas com os juros da dívida pública, a partir da segunda metade dos anos 1980, é explicado pelo aumento do déficit público e consequente endividamento (Rezende, 2001; Riani, 2002). Por outro lado, a decretação da moratória da dívida externa em 1986 acarretou na suspensão do pagamento dos juros e do principal da dívida. A partir da segunda moratória da dívida externa, decretada em 1989, essas despesas aumentaram sua participação relativa em comparação ao PIB: amortização da dívida (16,27\% em 1989 e 12,85\% em 2008) e juros e encargos da dívida (5,01\% em 1989 e 3,40\% em 2008).

A despesa com pessoal aumentou em termos reais de 3,54\% do PIB em 1990 para $4,01 \%$ em 2008 , e esse fato ocorreu devido ao aumento das despesas com servidores inativos (Ramos, 2001; Giambiagi, 2008). No tocante aos servidores ativos, mesmo deixando de conceder reajustes salariais generalizados para o funcionalismo público, o governo federal implementou ao longo do período do Plano Real uma política de reestruturação de algumas carreiras do serviço público, fato que levou à concessão de reajustes salariais diferenciados para esse bloco. Esse fato, aliado ao cumprimento de algumas sentenças judiciais, explica o crescimento da folha de servidores ativos da União no período analisado (Ramos, 2001).

Giambiagi (2008) e Garcia (2008) argumentam que as razões para o aumento das despesas do INSS de 0,83\% do PIB real em 1991 para 6,84\% do PIB real em 2007 se prendem a três causas. A primeira é o "efeito denominador" relacionado com o crescimento médio do PIB nos últimos anos. A segunda é a benevolência da

\footnotetext{
${ }^{4} \mathrm{Na}$ modalidade de despesa Amortização da Dívida, incluem-se os valores do refinanciamento da dívida mobiliária e da dívida contratual.
} 
legislação, que gerou impactos no contingente de beneficiários. E a terceira foi a política de aumentos reais do salário mínimo. Rezende (2001) argumenta que a elevação dessa despesa é explicada por fatores institucionais, por exemplo, a ampliação dos benefícios introduzida pela Constituição de 1988 e a manutenção da aposentadoria por tempo de serviço, e por fatores estruturais, como o envelhecimento natural da população e o aumento da expectativa de vida.

Tabela 1: Composição dos Gastos Públicos Federais (\% PIB real): 1980-2008

\begin{tabular}{|c|c|c|c|c|c|c|c|c|c|c|}
\hline Composição & 1980 & 1981 & 1982 & 1983 & 1984 & 1985 & 1986 & 1987 & 1988 & 1989 \\
\hline Pessoal & $0,75 \%$ & $0,94 \%$ & $0,80 \%$ & $0,76 \%$ & $0,65 \%$ & $0,78 \%$ & $0,74 \%$ & $0,78 \%$ & $1,07 \%$ & $1,60 \%$ \\
\hline Juros da Dívida & $0,36 \%$ & $0,18 \%$ & $0,25 \%$ & $0,34 \%$ & $0,22 \%$ & $0,61 \%$ & $1,81 \%$ & $0,53 \%$ & $2,18 \%$ & $5,01 \%$ \\
\hline $\begin{array}{l}\text { Transferências a } \\
\text { Estados/ Municípios }\end{array}$ & $0,67 \%$ & $0,68 \%$ & $1,38 \%$ & $1,39 \%$ & $1,46 \%$ & $1,84 \%$ & $2,08 \%$ & $2,11 \%$ & $2,12 \%$ & $2,01 \%$ \\
\hline Ben. Previdenciários & $0,54 \%$ & $0,57 \%$ & $0,63 \%$ & $0,60 \%$ & $0,54 \%$ & $0,62 \%$ & $0,61 \%$ & $0,67 \%$ & $0,82 \%$ & $1,19 \%$ \\
\hline $\begin{array}{l}\text { Demais Despesas } \\
\text { Correntes }\end{array}$ & $2,31 \%$ & $1,94 \%$ & $2,30 \%$ & $2,70 \%$ & $2,89 \%$ & $2,10 \%$ & $2,46 \%$ & $3,11 \%$ & $3,29 \%$ & $4,46 \%$ \\
\hline Investimentos & $0,55 \%$ & $1,11 \%$ & $0,72 \%$ & $0,56 \%$ & $0,40 \%$ & $0,50 \%$ & $0,94 \%$ & $1,15 \%$ & $1,07 \%$ & $0,50 \%$ \\
\hline Inversões Financeiras & $0,08 \%$ & $0,12 \%$ & $0,29 \%$ & $0,24 \%$ & $0,26 \%$ & $0,35 \%$ & $1,60 \%$ & $0,58 \%$ & $0,37 \%$ & $0,52 \%$ \\
\hline Amortização da Dívida & $0,20 \%$ & $0,08 \%$ & $0,13 \%$ & $0,32 \%$ & $0,19 \%$ & $0,15 \%$ & $0,47 \%$ & $0,70 \%$ & $0,71 \%$ & $16,27 \%$ \\
\hline Composição & 1990 & 1991 & 1992 & 1993 & 1994 & 1995 & 1996 & 1997 & 1998 & 1999 \\
\hline Pessoal & $3,54 \%$ & $2,58 \%$ & $2,39 \%$ & $3,63 \%$ & $4,38 \%$ & $4,71 \%$ & $4,25 \%$ & $4,16 \%$ & $4,30 \%$ & $4,25 \%$ \\
\hline Juros da Dívida & $2,09 \%$ & $0,35 \%$ & $1,62 \%$ & $2,07 \%$ & $2,36 \%$ & $2,09 \%$ & $2,03 \%$ & $1,97 \%$ & $2,76 \%$ & $3,74 \%$ \\
\hline $\begin{array}{l}\text { Transferências a } \\
\text { Estados/Municípios }\end{array}$ & $2,38 \%$ & $2,01 \%$ & $2,16 \%$ & $2,53 \%$ & $2,88 \%$ & $2,69 \%$ & $2,67 \%$ & $2,80 \%$ & $3,36 \%$ & $3,45 \%$ \\
\hline Ben. Previdenciários & $0,99 \%$ & $0,83 \%$ & $0,89 \%$ & $3,82 \%$ & $4,08 \%$ & $4,05 \%$ & $4,31 \%$ & $4,34 \%$ & $4,80 \%$ & $4,79 \%$ \\
\hline $\begin{array}{l}\text { Demais Despesas } \\
\text { Correntes }\end{array}$ & $5,49 \%$ & $4,90 \%$ & $4,91 \%$ & $3,13 \%$ & $3,13 \%$ & $3,00 \%$ & $2,69 \%$ & $2,75 \%$ & $2,65 \%$ & $2,58 \%$ \\
\hline Investimentos & $0,79 \%$ & $0,89 \%$ & $0,74 \%$ & $1,03 \%$ & $0,92 \%$ & $0,59 \%$ & $0,60 \%$ & $0,70 \%$ & $0,74 \%$ & $0,57 \%$ \\
\hline Inversões Financeiras & $1,63 \%$ & $1,39 \%$ & $3,63 \%$ & $1,06 \%$ & $1,37 \%$ & $0,93 \%$ & $1,26 \%$ & $5,96 \%$ & $6,39 \%$ & $4,68 \%$ \\
\hline Amortização da Dívida & $33,50 \%$ & $7,59 \%$ & $10,14 \%$ & $13,47 \%$ & $14,54 \%$ & $11,92 \%$ & $12,15 \%$ & $13,82 \%$ & $19,82 \%$ & $24,43 \%$ \\
\hline Composição & 2000 & 2001 & 2002 & 2003 & 2004 & 2005 & 2006 & 2007 & 2008 & \\
\hline Pessoal & $4,33 \%$ & $4,41 \%$ & $4,46 \%$ & $4,08 \%$ & $4,04 \%$ & $3,85 \%$ & $3,96 \%$ & $4,49 \%$ & $4,01 \%$ & \\
\hline Juros da Dívida & $2,89 \%$ & $3,56 \%$ & $3,28 \%$ & $3,39 \%$ & $3,36 \%$ & $3,67 \%$ & $5,60 \%$ & $5,40 \%$ & $3,40 \%$ & \\
\hline $\begin{array}{l}\text { Transferências a } \\
\text { Estados/Municípios }\end{array}$ & $3,84 \%$ & $4,03 \%$ & $4,37 \%$ & $4,14 \%$ & $4,17 \%$ & $4,81 \%$ & $4,70 \%$ & $5,25 \%$ & $4,94 \%$ & \\
\hline Ben. Previdenciários & $4,82 \%$ & $5,05 \%$ & $5,20 \%$ & $5,60 \%$ & $5,56 \%$ & $5,82 \%$ & $5,99 \%$ & $6,84 \%$ & $5,87 \%$ & \\
\hline $\begin{array}{l}\text { Demais Despesas } \\
\text { Correntes }\end{array}$ & $2,73 \%$ & $2,75 \%$ & $2,83 \%$ & $2,61 \%$ & $2,74 \%$ & $3,04 \%$ & $3,10 \%$ & $3,33 \%$ & $2,77 \%$ & \\
\hline Investimentos & $0,75 \%$ & $0,98 \%$ & $0,60 \%$ & $0,33 \%$ & $0,49 \%$ & $0,71 \%$ & $0,73 \%$ & $0,39 \%$ & $0,21 \%$ & \\
\hline Inversões Financeiras & $0,85 \%$ & $1,38 \%$ & $1,24 \%$ & $1,21 \%$ & $0,98 \%$ & $0,89 \%$ & $0,99 \%$ & $1,02 \%$ & $1,13 \%$ & \\
\hline Amortização da Dívida & $25,66 \%$ & $18,51 \%$ & $18,10 \%$ & $23,68 \%$ & $19,71 \%$ & $22,45 \%$ & $18,43 \%$ & $18,16 \%$ & $12,85 \%$ & \\
\hline
\end{tabular}

Fonte: SIAFI — STN/CCONT/GEINC e IPEA. Nota: Excluídas as operações intraorçamentárias. Elaboração do autor.

No tocante às transferências governamentais $(2,01 \%$ em 1989 e 4,94\% em 2008), observa-se no início dos anos 1990 um processo descentralização promovi- 
do pelo governo central em direção aos Estados e, principalmente, aos Municípios, tornando majoritário o número de ações federais executadas por esses níveis de governo, por exemplo, saúde, assistência social, segurança alimentar, educação básica, esporte e cultura, apoio à agricultura familiar e reforma agrária, saneamento e habitação, segurança pública, entre outras áreas, mediante transferências de recursos do orçamento da União (Garcia, 2008).

O crescimento das demais despesas correntes, a partir de 1993, está associado à elevação de gastos com manutenção da administração pública e de estradas federais, execução direta do governo federal em saúde e educação, assim como programas de transferências de renda (por exemplo, o programa governamental Bolsa Família), dentre outros (Garcia, 2008).

\section{TRATAMENTO ECONOMÉTRICO}

\section{Teste de raiz unitária com quebra endógena}

Os testes tradicionais de raiz unitária possuem baixo poder na presença de quebras estruturais, tornando-se viesados no sentido da nãorejeição da hipótese nula de existência de raiz unitária quando a série é estacionária. Perron (1989) propôs alterações nos testes de raízes unitárias no sentido de tratar a quebra estrutural como um evento exógeno, conhecendo-se sua data de ocorrência. Saikkonen e Lütkepohl (2002) e Lanne et al. (2002), por sua vez, propõem que as quebras estruturais podem ocorrer ao longo de um número de períodos e expõe uma transição suave para um novo nível. Assim, uma função de mudança de nível, que é conhecida pela forma não linear geral $f_{t}(\theta)^{\prime} \gamma$ é acrescentada ao termo determinístico $\mu_{t}$ do processo gerador de dados. Portanto, o modelo é expresso pela seguinte regressão:

$$
q_{t}=\mu_{0}+\mu_{1} t+f(\theta)^{\prime} \gamma+v_{t}
$$

onde $\theta$ e $\gamma$ são parâmetros escalares desconhecidos, ao passo que $v_{t}$ são erros residuais gerados por um processo $\mathrm{AR}(\mathrm{p})$ com possível raiz unitária. A mudança na função $f_{t}(\theta)^{\prime} \gamma$ pode ser: (i) uma variável dummy de mudança simples com data de mudança $T_{b}$ (shift dummy); (ii) baseada em uma função de distribuição exponencial que permite uma mudança gradual não linear para um novo nível começando no período $T_{b}$ (exponencial shift); (iii) uma função racional no operador de defasagem aplicado a uma dummy de mudança (rational shift). Saikkonen e Lutkepohl (2002) e Lanne et al. (2002) propuseram teste de raiz unitária baseado na estimação do termo determinístico por mínimos quadrados generalizados (GLS) e a subtração dessa tendência da série original. Em seguida, um teste ADF é desenvolvido para as séries ajustadas. Se a data da quebra é desconhecida, recomenda-se a escolha de uma ordem de defasagens maior no primeiro passo e, então, apanhar a data de quebra 
que minimiza a soma dos erros quadrados generalizada do modelo em primeiras diferenças. Valores críticos foram tabulados por Lanne et al. (2002).

\section{Causalidade Multivariada}

A análise de causalidade inicia-se pela estimação de um modelo vetorial autorregressivo (VAR) envolvendo todas as variáveis mencionadas anteriormente. O conceito de causalidade no sentido de Granger está associado à ideia de precedência temporal entre variáveis. Assim, se $y_{t}$ contém informação passada que ajuda na previsão de $z_{t}$, e se essa informação não está contida em outras séries usadas no modelo, então $y_{t}$ Granger-causa $z_{t}$ Granger, 1969). O VAR em forma reduzida de dimensão $p$ pode ser escrito com:

$$
X_{t}=A_{0}+A_{1} X_{t-1}+A_{2} X_{t-2}+\ldots+A_{p} X_{t-p}+\zeta_{t}
$$

onde, $X_{t}$ é um vetor de variáveis estacionárias, $p$ é o número de defasagens, $A_{0}$ é um vetor de interceptos, $A_{i}$ são matrizes de coeficientes e $\zeta_{t}$ é um vetor de resíduos não-autocorrelacionados e homocedásticos. No caso, o vetor $X_{t}$ contém as séries dos gastos públicos, classificados por grupo de despesa. A seleção da ordem de defasagem é feita pelos critérios de informação. Como a análise de causalidade não requer a estimação de parâmetros estruturais, não há necessidade de se adotar alguma estratégia de identificação em (4).

A causalidade de Granger da variável $j$ para a variável $h$ é avaliada testando a hipótese nula de que os coeficientes da variável $j$ em todas as suas defasagens são, simultaneamente, estatisticamente iguais a zero na equação em que $b$ é a variável dependente. Caso a hipótese nula seja rejeitada, conclui-se que a variável $j$ Granger-causa a variável $h$.

Caso as variáveis em $X_{t}$ não sejam estacionárias, deve-se testar cointegração. Nesse caso, havendo cointegração entre as variáveis, utiliza-se o vetor cointegrante para obter uma combinação linear estacionária entre as variáveis e estima-se um modelo vetorial autorregressivo de correção de erros, chamado VEC. A significância estatística do termo de correção de erros também deve ser considerada na condução do teste de causalidade.

A cointegração pode ser testada seguindo o procedimento sugerido por Johansen $(1988,1991,1992,1994,1995)$ O teste consiste em modelar séries temporais como uma regressão de posto reduzido em que se calculam as estimativas de máxima verossimilhança do vetor cointegrante no modelo de correção de erros multivariado com erros gaussianos. O teste requer a estimação da representação de correção de erros dada por:

$$
\Delta X_{t}=\mu+\pi X_{t-1}+\sum_{i=1}^{p-1} \pi_{i} \Delta X_{t-i}+\varepsilon_{t}
$$


onde $X_{t}$ é um vetor coluna $(m \times 1)$ de variáveis; $\mu$ é um vetor $(n \times 1)$ de termos constantes; $\pi$ e $\pi_{t}$ representam matrizes de coeficientes; $p$ é a ordem das defasagens; e o resíduo $\varepsilon_{t}$ é não autocorrelacionado e homocedástico. A matriz coeficientes $\pi$ é conhecida como matriz cointegrante e contém informações sobre o equilíbrio de longo prazo entre as variáveis. O número de autovalores de $\pi$ que são estatisticamente diferentes de zero, o que corresponde ao posto de $\pi$, fornece o número de vetores cointegrantes no sistema. Johansen propõe a estatística do traço para se testar quantos vetores cointegrantes existem em (3). Essa estatística é expressa por:

$$
\lambda_{\text {traco }}(r)=-T \sum_{i=r+1}^{n} \ln \left(1-\hat{\lambda}_{i}\right)
$$

onde $\hat{\lambda}_{i}$ são os valores estimados dos autovalores obtidos da matriz $\pi$ e $T$ é o número de observações. O teste segue um procedimento recursivo, onde a hipótese nula é de que há, no máximo, $r$ vetores cointegrantes. Os valores críticos foram tabulados por Johansen (1995).

\section{RESULTADOS}

\section{Teste de raiz unitária com quebra endógena}

Os resultados do teste de Saikkonen e Lütkepohl (2002), doravante denominado SL, são apresentados nas Tabelas 2, 3 e 4 . A escolha do tipo de mudança foi baseada na análise gráfica de cada série, e as datas de quebras estruturais obtidas endogenamente estão em conformidade com os resultados apresentados na Tabela 1.

$\mathrm{Na}$ Tabela 2, o teste SL indica que a série do PIB real é integrada de ordem um, I(1). A quebra estrutural de 1995 está associada à implantação do Plano Real no ano anterior, no qual uma das etapas da implantação era o estabelecimento do equilíbrio das contas do governo, com o objetivo de eliminar uma das principais causas da inflação brasileira.

No tocante às despesas correntes, os resultados do teste SL na Tabela 3 indicam que as séries das variáveis juros da dívida e despesa previdenciárias tornam-se estacionárias em nível, sendo consideradas $\mathrm{I}(0)$, ao passo que as demais séries tornam-se estacionárias em primeiras diferenças, sendo consideradas I(1).

Os resultados do teste SL nas despesas de capital são reportados na Tabela 4 e indicam que a série de investimentos públicos é integrada de ordem um, I(1). A série de inversões financeiras torna-se estacionária em nível no modelo com constante e tendência, ao passo que a série de amortização da dívida pública torna-se estacionária em nível no modelo com constante. 
Tabela 2: Teste SL de raiz unitária com quebra estrutural. PIB real

\begin{tabular}{c|c|c|c|c}
\hline Variável & $\begin{array}{c}\text { Característica } \\
\text { do Modelo }\end{array}$ & Tipo de mudança & Quebra & $\begin{array}{c}\text { Estatística } \\
\text { de teste }\end{array}$ \\
\hline pib $_{t}$ & C (2 lags) & Rational shift & 1995 & $-2,40$ \\
\hline pib $_{t}$ & C,T (2 lags) & Rational shift & 1995 & $-2,40$ \\
\hline$\Delta p i b_{t}$ & C (2 lags) & Rational shift & 1995 & $-4,32^{*}$ \\
\hline$\Delta p i b_{t}$ & C,T (2 lags) & Rational shift & 1995 & $-7,18^{*}$ \\
\hline
\end{tabular}

Nota: Na modelagem da quebra endógena, considerou-se dummy de nível. "C" significa constante. " $T$ " significa tendência determinística. " $\Delta$ " significa operador de primeiras diferenças. $\left({ }^{*}\right)$ significância a $1 \%$; $\left({ }^{*}\right)$ significância a 5\%. Contagem inicial máxima de 10 defasagens. Os valores críticos do teste (Lanne et al., 2002) são os seguintes: (i) modelo com constante: $-3,48(1 \%)$ e -2,88 (5\%); (ii) modelo com constante e tendência determinística: $-3,55(1 \%)$ e $-3,03(5 \%)$.

Tabela 3: Teste SL de raiz unitária com quebra estrutural. Despesas Correntes

\begin{tabular}{|c|c|c|c|c|}
\hline Variável & $\begin{array}{c}\text { Característica } \\
\text { do Modelo }\end{array}$ & Tipo de Modelo & Quebra & $\begin{array}{c}\text { Estatística } \\
\text { de teste }\end{array}$ \\
\hline pess $_{t}$ & C (2 lags) & Rational shift & 1990 & $-2,83$ \\
\hline pess $_{t}$ & C,T (2 lags) & Rational shift & 1990 & $-2,78$ \\
\hline$\Delta$ pess $_{t}$ & C (2 lags) & Rational shift & 1990 & $-4,42^{*}$ \\
\hline$\Delta$ pess $_{t}$ & C,T (2 lags) & Rational shift & 1990 & $-4,72^{*}$ \\
\hline juros $_{t}$ & C (2 lags) & Shift dummy & 1986 & $-1,32$ \\
\hline juros $_{t}$ & C,T (1 lag) & Shift dummy & 1986 & $-5,59 *$ \\
\hline$\Delta$ juros $_{t}$ & C (4 lags) & Shift dummy & 1986 & $-4,91 *$ \\
\hline$\Delta$ juros $_{t}$ & C,T (2 lag) & Shift dummy & 1986 & $-4,98^{*}$ \\
\hline transf & C (2 lags) & Shift dummy & 1985 & 0,27 \\
\hline transf & C,T (2 lags) & Shift dummy & 1985 & $-2,88$ \\
\hline$\Delta$ transf $_{t}$ & C (2 lags) & Shift dummy & 1987 & $-3,98 * *$ \\
\hline$\Delta$ transf $_{t}$ & C,T (2 lags) & Shift dummy & 1987 & $-3,44^{* *}$ \\
\hline prev $_{t}$ & C (0 lags) & Rational shift & 1993 & $-3,58^{*}$ \\
\hline prev $_{t}$ & C,T (2 lags) & Rational shift & 1993 & $-2,74$ \\
\hline$\Delta$ prev $_{t}$ & C (1 lag) & Rational shift & 1993 & $-3,68^{*}$ \\
\hline$\Delta$ prev $_{t}$ & C,T (0 lags) & Rational shift & 1993 & $-1,21$ \\
\hline corr $_{t}$ & C (1 lag) & Shift dummy & 1993 & $-1,94$ \\
\hline corr $_{t}$ & C,T (4 lags) & Shift dummy & 1993 & $-0,71$ \\
\hline$\Delta$ corr $_{t}$ & C (3 lag) & Shift dummy & 1993 & $-5,20 *$ \\
\hline$\Delta$ corr $_{t}$ & C,T (3 lags) & Shift dummy & 1993 & $-6,96^{*}$ \\
\hline
\end{tabular}

Nota: Na modelagem da quebra endógena, considerou-se dummy de nível. "C" significa constante. " $T$ " significa tendência determinística. " $\Delta$ " significa operador de primeiras diferenças. $\left({ }^{*}\right)$ significância a $1 \%$; $\left({ }^{*}\right)$ significância a 5\%. Contagem inicial máxima de 10 defasagens. Os valores críticos do teste (Lanne et al., 2002) são os seguintes: (i) modelo com constante: $-3,48(1 \%)$ e -2,88 (5\%); (ii) modelo com constante e tendência determinística: $-3,55(1 \%)$ e $-3,03(5 \%)$. 
Tabela 4: Teste SL de raiz unitária com quebra estrutural. Despesas de Capital

\begin{tabular}{c|c|c|c|c}
\hline Variável & $\begin{array}{c}\text { Característica } \\
\text { do Modelo }\end{array}$ & Tipo de Modelo & Quebra & $\begin{array}{c}\text { Estatística } \\
\text { de teste }\end{array}$ \\
\hline$i f_{t}$ & C (0 lag) & Shift dummy & 2000 & $-1,95$ \\
\hline$i f_{t}$ & C,T (0 lag) & Shift dummy & 2000 & $-3,69^{*}$ \\
\hline$\Delta i f_{t}$ & C (3 lags) & Shift dummy & 2000 & $-2,36$ \\
\hline$\Delta i f_{t}$ & C,T (3 lags) & Shift dummy & 2000 & $-3,52^{*}$ \\
\hline$i n v_{t}$ & C (1 lag) & Shift dummy & 1989 & $-2,84$ \\
\hline$i n v_{t}$ & C,T (1 lag) & Shift dummy & 1989 & $-2,88$ \\
\hline$\Delta i n v_{t}$ & C (3 lags) & Shift dummy & 1989 & $-3,95^{*}$ \\
\hline$\Delta i n v_{t}$ & C,T (3 lags) & Shift dummy & 1989 & $-3,42^{* *}$ \\
\hline div $_{t}$ & C (0 lags) & Shift dummy & 1989 & $-3,03^{* *}$ \\
\hline div $_{t}$ & C,T (0 lags) & Shift dummy & 1989 & $-2,14$ \\
\hline$\Delta d i v_{t}$ & C (0 lag) & Shift dummy & 1989 & $-6,28^{*}$ \\
\hline$\Delta d i v_{t}$ & C,T (3 lags) & Shift dummy & 1989 & $-1,50$ \\
\hline
\end{tabular}

Nota: Na modelagem da quebra endógena, considerou-se dummy de nível. " $\mathrm{C}$ " significa constante. " $T$ " significa tendência determinística. " $\Delta$ " significa operador de primeiras diferenças. $\left({ }^{*}\right)$ significância a $1 \%$; $\left({ }^{*}\right)$ significância a $5 \%$. Contagem inicial máxima de 10 defasagens. Os valores críticos do teste (Lanne et al., 2002) são os seguintes: (i) modelo com constante: $-3,48(1 \%) ;-2,88(5 \%)$; $-2,58(10 \%)$; (ii) modelo com constante e tendência determinística: $-3,55(1 \%) ;-3,03(5 \%) ;-2,76(10 \%)$.

\section{Causalidade multivariada}

Procedeu-se à modelagem de quebras estruturais no teste do traço de Johansen, com a inclusão máxima de duas variáveis dummies de nível nas categorias econômicas de despesas, devido à restrição dada na aplicação desse teste, considerando-se o caso de presença de constante e tendência linear. A primeira variável dummy, comum em cada categoria, visa modelar o efeito do Plano Real sobre o crescimento econômico, assumindo os valores $D_{1995}=0$ entre os anos $1980-1994$, e $D_{1995}=1$ entre os anos 1995-2008. Nas despesas correntes, observou-se a inclusão de mais uma variável dummy de nível assumindo os seguintes valores: $D_{1986}=0$ entre os anos 1980-1985, e $D_{1986}=1$ entre os anos 1986-2008. Nas despesas de capital, observou-se também a inclusão de outra variável dummy de nível assumindo os seguintes valores: $D_{1989}=0$ entre os anos $1980-1988$, e $D_{1989}=0$ entre os anos 1989-2008.

Os resultados do teste de cointegração de Johansen com quebra estrutural são reportados nas Tabelas 5 e 6, e indicam a existência de relação de equilíbrio de longo prazo entre as variáveis analisadas, ou seja, não se rejeita a hipótese de presença de vetores cointegração ${ }^{5}$.

${ }^{5} \mathrm{O}$ fato do teste de Johansen não rejeitar a hipótese de 4 relações de cointegração, no tocante às despesas correntes, ou de 3 relações de cointegração, no caso de despesas de capital, não significa que 
Tabela 5: Resultados do teste de cointegração de Johansen com quebra estrutural (Johansen Trace Test). Despesas Correntes e PIB

\begin{tabular}{c|l|l|l|l|l}
\hline rank $(r)$ co-integrante & \multicolumn{1}{|c|}{ LR } & Valor-p & $90 \%$ & $95 \%$ & \multicolumn{1}{c}{$99 \%$} \\
\hline$r=0$ & $464,32^{*}$ & 0,0000 & 140,42 & 146,07 & 157,08 \\
\hline$r \leq 1$ & $275,38^{*}$ & 0,0000 & 108,02 & 113,03 & 122,85 \\
\hline$r \geq 2$ & $181,60^{*}$ & 0,0000 & 79,44 & 83,81 & 92,42 \\
\hline$r \leq 3$ & $96,44^{*}$ & 0,0000 & 54,78 & 58,48 & 65,85 \\
\hline$r \leq 4$ & $51,96^{*}$ & 0,0000 & 33,90 & 36,90 & 42,97 \\
\hline$r \leq 5$ & 16,46 & 0,0992 & 16,44 & 18,58 & 23,06 \\
\hline
\end{tabular}

Nota: Inclusão de constante e tendência linear. * Significa rejeição da hipótese nula de posto $r$ cointegrante ao nível de significância de $1 \%$. Selecionaram-se duas defasagens ótimas, segundo os critérios de informação AIC, SC, HQ e FPE. Inclusão de dummies de nível para os anos 1986 e 1995.

Tabela 6: Resultados do teste de cointegração de Johansen com quebra estrutural (Johansen Trace Test). Despesas de Capital e PIB

\begin{tabular}{c|c|c|c|c|c}
\hline rank $(r)$ co-integrante & LR & Valor-p & $90 \%$ & $95 \%$ & $99 \%$ \\
\hline$r=0$ & $233,33^{*}$ & 0,0000 & 79,44 & 83,81 & 92,42 \\
\hline$r=1$ & $121,36^{*}$ & 0,0000 & 54,78 & 58,48 & 65,85 \\
\hline$r=2$ & $59,11^{*}$ & 0,0001 & 33,90 & 36,90 & 42,97 \\
\hline$r=0$ & $23,99^{*}$ & 0,0070 & 16,44 & 18,58 & 23,06 \\
\hline
\end{tabular}

Nota: Inclusão de constante e tendência linear. ${ }^{*}$ - Significa rejeição da hipótese nula de posto $r$ cointegrante ao nível de significância de $1 \%$. Selecionaram-se três defasagens ótimas, segundo os critérios de informação AIC, SC, HQ e FPE. Inclusão de dummies de nível para os anos 1989 e 1995.

De acordo com os resultados apresentados nas Tabelas 5 e 6, a análise de causalidade de Granger deverá ser desenvolvida estimando-se um modelo VEC. O teorema da representação de Granger postula que se as séries de tempo são cointegradas, então a regressão entre elas pode ser expressa com um modelo de correção de erros (Engle e Granger, 1987). Logo, a causalidade de Granger deve ser investigada inserindo-se o resíduo defasado de um período do vetor cointegrante, chamado mecanismo de correção de erros (MCE). Um termo de correção de erro significante implica relação de causalidade de Granger de longo prazo das variáveis explicativas para as variáveis dependentes (Granger, 1988).

As Tabelas 7 e 8 apresentam os resultados do teste de causalidade de Granger baseados na estimação de modelo VEC referente às despesas correntes e de capital. No tocante às despesas correntes, o modelo VEC foi estimado com quatro vetores

elas efetivamente existam de forma independente, ou seja, que elas sejam identificadas. Do ponto de vista da interpretação dos resultados, por exemplo, acredita-se ser difícil justificar quatro relações diferentes de equilíbrio de longo prazo entre essas variáveis, o que algebricamente acabaria envolvendo restrições de identificação. 
cointegrantes, e a hipótese de exogeneidade não foi rejeitada para as despesas com benefícios previdenciários. No caso das despesas de capital, o modelo VEC foi estimado com três vetores de cointegração, e todas as variáveis foram consideradas endógenas no sistema ${ }^{6}$.

Vários coeficientes estimados de variáveis diferenciadas e defasadas e dos termos de correção de erros mostraram-se significantes e confirmaram a relação de causalidade de Granger no curto e no longo prazo. Quanto às despesas correntes, as variáveis de ajuste que garantem a relação de equilíbrio de longo prazo com o PIB real são as despesas com pessoal, juros da dívida, transferências governamentais e demais despesas correntes.

Observa-se relação de bicausalidade de Granger entre as demais despesas correntes e o PIB real, ao nível de significância de $1 \%$. Por um lado, a causalidade de Granger das demais despesas correntes para o PIB real é negativa, confirmando a prevalência dos efeitos não keynesianos da política fiscal, de modo que uma contração fiscal dessas despesas pode provocar efeitos expansionistas sobre o PIB real da economia, conforme sugerido por Giambiagi (2008). Por outro lado, a causalidade de Granger do PIB real para as demais despesas correntes é positiva no curto prazo, confirmando a hipótese da Lei de Wagner, a qual postula que o crescimento da renda per-capita (ou o desenvolvimento econômico, em termos gerais) exige a participação cada vez maior do governo na oferta de bens públicos.

Observa-se relação de causalidade de Granger positiva e unidirecional do PIB real para as transferências governamentais ao nível de significância de $5 \%$, confirmando a prevalência da hipótese wagneriana. Esse resultado confirma, em parte, a evidência empírica obtida por Barro (1989) de que a Lei de Wagner se aplica somente às transferências governamentais, mas não para outros tipos de gastos. Assim, as transferências de recursos federais aos Estados, Municípios e Distrito Federal são influenciadas pela trajetória de crescimento real da economia que determina o repasse de recursos a esses entes da Federação.

As despesas de benefícios previdenciários Granger-causam o PIB real ao nível de significância de $5 \%$, sendo essa relação de causalidade negativa, significando que a elevada despesa previdenciária impacta negativamente o crescimento real da economia, confirmando-se a hipótese dos efeitos não keynesianos da política fiscal nesse grupo de despesa. Vários fatores podem ser responsáveis por esse resultado, por exemplo, uma política de aumento do salário mínimo pode comprometer a capacidade econômico-financeira das empresas, resultando em fechamento de empresas e aumento do desemprego, bem como o impacto negativo sobre as contas

\footnotetext{
${ }^{6}$ Em cada modelo VEC estimado, considerou-se a inclusão de três variáveis dummies de nível, em conformidade com os resultados obtidos no teste de raiz unitária com quebra estrutural (Saikkonen e Lutkepohl, 2002), Tabela 1. Nas despesas correntes, utilizou-se outra variável dummy, assumindo os seguintes valores: $D_{1990}=0$ entre os anos 1980-1989, e $D_{1990}=1$ entre os anos 1990-2008. Nas despesas de capital, observou-se também a inclusão de outra variável dummy assumindo os seguintes valores: $D_{2000}=0$ entre os anos 1980-1999, e $D_{2000}=1$ entre os anos 2000-2008.
} 
públicas, uma vez que os benefícios previdenciários possuem forte rigidez orçamentária devido a fatores institucionais.

Tabela 7: Resultados do teste de causalidade de Granger aplicado ao VEC.

Despesas Correntes e PIB

\begin{tabular}{|c|c|c|c|c|c|c|}
\hline \multirow{2}{*}{$\begin{array}{c}\text { Variáveis } \\
\text { Independentes }\end{array}$} & \multicolumn{6}{|c|}{ Variáveis Dependentes } \\
\hline & $\Delta p_{i}$ & $\Delta$ corr $_{t}$ & $\Delta$ juros $_{t}$ & $\Delta$ pess $_{t}$ & $\Delta$ prev $_{t}$ & $\Delta$ transf $_{t}$ \\
\hline$\Delta p_{i} b_{t}$ & - & $\begin{array}{c}7,90 \\
{\left[0,0049^{*}\right]}\end{array}$ & $\begin{array}{c}0,00 \\
{[0,9637]}\end{array}$ & $\begin{array}{c}0,12 \\
{[0,7191]}\end{array}$ & $\begin{array}{c}0,00 \\
{[0,9883]}\end{array}$ & $\begin{array}{c}4,69 \\
{\left[0,0303^{* *}\right]}\end{array}$ \\
\hline$\Delta$ corr $_{t}$ & $\begin{array}{c}19,38 \\
{\left[0,0000^{*}\right]}\end{array}$ & - & $\begin{array}{c}2,60 \\
{[0,1063]}\end{array}$ & $\begin{array}{c}3,49 \\
{[0,0614]}\end{array}$ & $\begin{array}{c}0,06 \\
{[0,7966]}\end{array}$ & $\begin{array}{c}4,96 \\
{[0,0259 * *]}\end{array}$ \\
\hline$\Delta$ juros $_{t}$ & $\begin{array}{c}0,31 \\
{[0,5763]}\end{array}$ & $\begin{array}{c}0,43 \\
{[0,5090]}\end{array}$ & - & $\begin{array}{c}0,08 \\
{[0,7727]}\end{array}$ & $\begin{array}{c}2,69 \\
{[0,1008]}\end{array}$ & $\begin{array}{c}0,07 \\
{[0,7803]}\end{array}$ \\
\hline$\Delta$ pess $_{t}$ & $\begin{array}{c}0,88 \\
{[0,3456]}\end{array}$ & $\begin{array}{c}1,28 \\
{[0,2577]}\end{array}$ & $\begin{array}{c}0,18 \\
{[0,6700]}\end{array}$ & - & $\begin{array}{c}0,01 \\
{[0,9198]}\end{array}$ & $\begin{array}{c}1,02 \\
{[0,3122]}\end{array}$ \\
\hline$\Delta p r e v_{t}$ & $\begin{array}{c}4,09 \\
{\left[0,0430^{* *}\right]}\end{array}$ & $\begin{array}{c}11,15 \\
{\left[0,0008^{*}\right]}\end{array}$ & $\begin{array}{c}0,25 \\
{[0,6162]}\end{array}$ & $\begin{array}{c}0,40 \\
{[0,5237]}\end{array}$ & - & $\begin{array}{c}2,74 \\
{[0,0979]}\end{array}$ \\
\hline$\Delta$ transf $_{t}$ & $\begin{array}{c}2,67 \\
{[0,1019]}\end{array}$ & $\begin{array}{c}3,74 \\
{[0,0528]}\end{array}$ & $\begin{array}{c}0,02 \\
{[0,8674]}\end{array}$ & $\begin{array}{c}0,34 \\
{[0,5576]}\end{array}$ & $\begin{array}{c}0,73 \\
{[0,3907]}\end{array}$ & - \\
\hline
\end{tabular}

Nota: VEC Granger Causality/Block Exogeneity Wald Tests. Observações incluídas: 24. Os valores em colchetes são os valores-p. Todos os outros valores são testes $\chi^{2}$ da Causalidade de Granger. $\left({ }^{*}\right)$ significância a $1 \%,\left(^{* *}\right)$ significância a $5 \%$. " $\Delta$ " significa operador de primeiras diferenças. Selecionou-se uma defasagem ótima no modelo VEC estimado. Inclusão de dummies de nível para os anos 1986, 1990 e 1995.

No tocante às despesas de capital, os resultados sugerem que todos os grupos de natureza de despesa são variáveis de ajuste que garantem a relação de equilíbrio de longo prazo com o PIB real. Os investimentos públicos Granger-causam unidirecionalmente o PIB real, ao nível de significância de $1 \%$, sendo essa relação de causalidade temporal positiva. Assim, aumentos nos investimentos públicos contribuem para o crescimento da economia brasileira, confirmando-se a hipótese keynesiana dos gastos públicos. Esse resultado evidencia a importância dos investimentos públicos em estimular o crescimento econômico tendo em vista que variações passadas no investimento público são relevantes para a explicação das mudanças contemporâneas do crescimento real do PIB. Diversas correntes atuais de pensamento argumentam que o baixo investimento público nas últimas duas décadas é um dos responsáveis pelo fato de o país não ter tido uma taxa de crescimento maior da sua economia nesse período (Giambiagi, 2008; Afonso e Biasoto, 2007).

Observa-se relação de causalidade de Granger unidirecional e negativa das despesas com amortização da dívida pública para o PIB real ao nível de significância de $1 \%$, mostrando que o elevado endividamento público impacta negativamente o PIB real. Esse resultado confirma os argumentos de Giambiagi (2008) de que 
um dos desafios para a retomada do crescimento econômico é conter a expansão da dívida pública. Portanto, confirma-se a hipótese dos efeitos não keynesianos da política fiscal nesse grupo de despesa, de modo que políticas fiscais contracionistas podem provocar efeitos expansionistas no PIB real da economia.

Tabela 8: Resultados do teste de causalidade de Granger aplicado ao VEC.

Despesas de Capital e PIB

\begin{tabular}{c|c|c|c|c}
\hline \multirow{2}{*}{$\begin{array}{c}\text { Variáveis } \\
\text { Independentes }\end{array}$} & \multicolumn{4}{|c}{ Variáveis Dependentes } \\
\cline { 2 - 5 } & $\Delta p i b_{t}$ & $\Delta i f_{t}$ & $\Delta i n v_{t}$ & $\Delta d i v_{t}$ \\
\hline$\Delta p i b_{t}$ & - & $\begin{array}{c}2,75 \\
{[0,4302]}\end{array}$ & $\begin{array}{c}7,59 \\
{[0,0550]}\end{array}$ & $\begin{array}{c}3,53 \\
{[0,3165]}\end{array}$ \\
\hline$\Delta i f_{t}$ & $\begin{array}{c}78,89 \\
{\left[0,0000^{*}\right]}\end{array}$ & - & $\begin{array}{c}13,33 \\
{\left[0,0040^{*}\right]}\end{array}$ & $\begin{array}{c}2,43 \\
{[0,4878]}\end{array}$ \\
\hline$\Delta i n v_{t}$ & $\begin{array}{c}45,78 \\
{\left[0,0000^{*}\right]}\end{array}$ & $\begin{array}{c}6,97 \\
{[0,0728]}\end{array}$ & - & 1,26 \\
\hline$\Delta d i v_{t}$ & $\begin{array}{c}54,35 \\
{\left[0,0000^{*}\right]}\end{array}$ & $\begin{array}{c}2,27 \\
{[0,5172]}\end{array}$ & $\begin{array}{c}13,53 \\
{\left[0,0036^{*}\right]}\end{array}$ & - \\
\hline
\end{tabular}

Nota: VEC Granger Causality/Block Exogeneity Wald Tests. Observações incluídas: 24. Os valores em colchetes são os valores-p. Todos os outros valores são testes $\chi^{2}$ da Causalidade de Granger. $\left(^{*}\right)$ significância a $1 \%$. " $\Delta$ " significa operador de primeiras diferenças. Selecionou-se uma defasagem ótima no modelo VEC estimado. Inclusão de dummies de nível para os anos 1989, 1995 e 2000.

\section{CONCLUSÕES}

A análise dos gastos públicos por grupo de natureza de despesa permite apurar a rigidez da composição dos gastos e a margem de flexibilidade do governo, no que se refere a sua política de gastos, bem como quantificar o alcance dos objetivos governamentais de promoção do crescimento econômico e de redistribuição da renda nacional. Por outro lado, no Brasil, assim como em muitos países, tem-se destacado a importância da condução de uma política fiscal anticíclica para as dificuldades impostas pela atual crise financeira internacional.

Esse estudo examinou a relação de precedência temporal entre gastos públicos federais e PIB, em termos reais, investigando-se a prevalência das hipóteses wagneriana e keynesiana dos gastos públicos, assim como a hipótese dos efeitos não keynesianos da política fiscal. O teste de cointegração de Johansen com quebra estrutural indicou a existência de relação de equilíbrio de longo prazo entre as variáveis analisadas, e o teste de causalidade de Granger desenvolvido em estrutura multivariada sugere importantes resultados na análise dos impactos da política fiscal sobre o crescimento econômico.

Sob o aspecto teórico, no longo prazo, os resultados empíricos sugerem a prevalência da hipótese keynesiana nos investimentos públicos, de modo que au- 
mentos nos investimentos públicos contribuem para estimular o crescimento econômico. Segundo, os resultados indicam a validade da hipótese dos efeitos não keynesianos da política fiscal nas despesas previdenciárias e amortização da dívida pública. Portanto, contrações fiscais nesses grupos de despesa devem provocar efeitos expansionistas no PIB real. Terceiro, os resultados obtidos sugerem a prevalência da hipótese wagneriana dos gastos públicos nas transferências governamentais, evidenciando-se a relação de causalidade entre o crescimento econômico e o repasse de recursos federais aos demais entes da Federação. Finalmente, observa-se relação de bicausalidade de Granger entre as demais despesas correntes e o PIB real.

Sob o aspecto de formulação de política fiscal anticíclica, no curto prazo a evidência empírica indica que os efeitos adversos da crise financeira internacional devem ser enfrentados por meio da elevação das despesas com investimentos públicos, controle da trajetória crescente das demais despesas correntes, benefícios previdenciários e da dívida pública, bem como aumento das transferências governamentais. Entretanto, uma vez que se observa um espaço limitado para a política fiscal anticíclica devido a um cenário de queda na arrecadação tributária para o ano de 2009, é importante conter o ritmo de crescimento do gasto público corrente, como forma de ampliar o espaço para o aumento do investimento público.

\section{REFERÊNCIAS BIBLIOGRÁICAS}

AFONSO, J. R; BIASOTO JR., G. Investimento público no Brasil: diagnósticos e proposições. Revista do BNDES, v. 14, n 27, junho de 2007.

ALESINA, A; PEROTTI, R. Fiscal expansions and fiscal adjustments in OECD countries. Economic Policy, v. 21, 1995.

. Fiscal adjustments in OECD countries: composition and macroeconomics effects. IMF Staff Papers, 44 (2), p. 210-248, 1997.

BARRO, R. A. Cross-Country Study of Growth, Saving and Government. NBER: Working Paper n. 2855, 1989.

BRASIL. Portaria Interministerial n ${ }^{\circ} 163$, de 4 de maio de 2001, do Ministério da Fazenda e do Ministério do Planejamento, Orçamento e Gestão.

BERTOLA, G; DRAZEN, A. Trigger points and budged cuts: explaining the effects of fiscal austerity. American Economic Review, v. 83, n 1, 1993.

CONTE, M. A; DARRAT, A. F. Economic growth and the expanding public sector: a reexamination. The Review of Economics and Statistics, v. 70, $\mathrm{n}^{\circ} 22,1988$.

ENGLE, R. F.; GRANGER, C. W. J. Co-integration and error correction: representation, estimation and testing. Econometrica, v. 55, $\mathrm{n}^{\circ} 2,1987$.

FASANO, U; WANG, Q. Fiscal expenditure policy and non-oil economic growth: evidence from GCC countries. IMF Working Paper $\mathrm{n}^{\circ}$ 195, 2001.

GHALI, K. H. Government spending and economic growth in Saudi Arabia. Journal of Economic Development, v. 22, $\mathrm{n}^{\circ} 2,1997$.

GARCIA, R. C. Despesas correntes da união: visões, omissões e opções. Instituto de Pesquisa Econômica Aplicada, Texto para Discussão n ${ }^{\circ} 1319$, janeiro de 2008.

GIAMBIAGI, F. 18 anos de política fiscal no Brasil: 1991-2008. Economia Aplicada, São Paulo, v. 12, n. 4, p. 535-580, outubro-dezembro de 2008.

GIAVAZZI. F; PAGANO, M. Can severe fiscal contractions be expansionary? Tales of two small euro- 
pean countries, in Olivier J. Blanchard e Stanley Fischer, orgs., NBER Macroeconomics Annual 1990. Cambridge, Massachusetts: MIT Press.

. Non-keynesian effects of fiscal policy changes: international evidence and the Swedish experience. Swedish Economic Policy Review 3, pp. 67-103, 1996.

GRANGER, C. W. J. Investigating causal relations by econometric models and cross-spectral models. Econometrica, v. 34, 1969.

. Some recent developments in the concept of causality, Journal of Econometrics, 39, p. 199-211, 1988.

HUANG, CHIUNG-JU. Government expenditure in China and Taiwan: do they follow wagner's law. Journal of Economic Development, v. 31, n. 2, 2006.

JOHANSEN, S. Statistical analysis of cointegration vectors, Journal of Economic Dynamics and Control 12, p. 231-254, 1988.

. Estimation and hypothesis test of cointegration vectors in Gaussian vector autoregressive models. Econometrica, v. 59, p. 1551-1580, 1991.

. Determination of cointegration rank in the presence of a linear trend, Oxford Bulletin of Economics and Statistics 54, p. 383-397, 1992.

. The role of the constant and linear terms in cointegration analysis of nonstationary time series, Econometric Reviews 13, p. 205-231, 1994

. Likelihood-based Inference in Cointegrated Vector Autoregressive Models, Oxford University Press, Oxford, 1995.

LANNE, M; SAIKKONEN, P; LÜTKEPOHL, H. Comparison of unit root tests for time series with level shifts. Journal of Time Series Analysis, 23, p. 667-685, 2002.

LOIZIDES, J; VAMVOUKAS, G. Government expenditure and economic growth: evidence from trivariate causality testing. Journal of Applied Economics, vol. III, $\mathrm{n}^{\circ}$ 1, 2005.

PERRON, P. The great crash, the oil price shock, and the unit root hypothesis. Econometrica, v. 57, n. 6. p. 1361-1401, 1989.

PEROTTI, R. Fiscal policy in good times and bad. The Quarterly Journal of Economics 114, p. 1399$-1436,1999$.

RAMOS, A. P. A política fiscal do plano real e o ajuste fiscal para 1999-2001. Revista de Economia Política, v. 21, n. 4 (84), outubro-dezembro 2001.

REZENDE, F. A. Finanças públicas. $2^{\text {a }}$ edição. São Paulo: Atlas, 2001.

RIANI, F. Economia do setor público: uma abordagem introdutória. $4^{a}$ edição. São Paulo: Atlas, 2002.

ROCHA, F; PICCHETTI, P. Fiscal adjustment in Brazil. Revista Brasileira de Economia, Rio de Janeiro, v. 57 (1), p. 239-252, janeiro-março 2003.

SAIKKONEN, P; LÜTKEPOHL, H. Testing for a unit root in a time series with a level shift at unknown time. Econometric Theory, 18, p. 313-348, 2002.

SINGH, B; SAHNI, B. S. Causality between public expenditure and national income. The Review of Economics and Statistics, v. 66, $\mathrm{n}^{\circ}$ 4, 1984.

WAGNER, Adolph. Finanzwissenschaft, Leipzig, 1890. 